\title{
Ethical Evaluation in Health Technology Assessment: A Challenge for Applied Philosophy
}

\section{Georges-Auguste Legault1,2, Jean-Pierre Béland2,3, Monelle Parent ${ }^{2}$, Suzanne K.-Bédard2,4, Christian A. Bellemare ${ }^{2,4}$, Louise Bernier1, Pierre Dagenais ${ }^{2,4,5}$, Charles-Étienne Daniel1,2, Hubert Gagnon ${ }^{2}$, Johane Patenaude ${ }^{2,5}$}

\author{
${ }^{1}$ Faculté de Droit, Université de Sherbrooke, Sherbrooke, Canada \\ ${ }^{2}$ Institut Interdisciplinaire d'Innovation Technologique (3IT) de l'Université de Sherbrooke, Sherbrooke, Canada \\ ${ }^{3}$ Unité d'Enseignement en Éthique, Département des Sciences Humaines, Université du Québec à Chicoutimi (UQAC), \\ Chicoutimi, Canada \\ ${ }^{4}$ Centre Intégré Universitaire de Santé et Services Sociaux (CIUSSS) de l'Estrie-Centre Hospitalier de l'Université de Sherbrooke \\ (CHUS), Sherbrooke, Canada \\ ${ }^{5}$ Faculté de Médecine et des Sciences de la Santé de l'Université de Sherbrooke, Sherbrooke, Canada \\ Email: georges-auguste.legault@usherbrooke.ca
}

How to cite this paper: Legault, G.-A. Béland, J.-P., Parent, M., K.-Bédard, S., Bellemare, C. A., Bernier, L., Dagenais, P., Daniel, C.-É., Gagnon, H., \& Patenaude, J. (2019). Ethical Evaluation in Health Technology Assessment: A Challenge for Applied Philosophy. Open Journal of Philosophy, 9, 331-351.

https://doi.org/10.4236/ojpp.2019.93022

Received: July 15, 2019

Accepted: August 20, 2019

Published: August 23, 2019

Copyright $\odot 2019$ by author(s) and Scientific Research Publishing Inc. This work is licensed under the Creative Commons Attribution International License (CC BY 4.0)

http://creativecommons.org/licenses/by/4.0/

\begin{abstract}
The integration of ethical analysis in Health Technology Assessment (HTA) has proven difficult to implement even though it is explicitly recognized as an important component of such assessments in HTA literature. When compared to the standardized scientific method for systematic reviews in HTA, the diversity of ethical analysis has been characterized as a fundamental barrier to the integration of ethics. The present paper aims to identify the theoretical and practical differences between the approaches underpinning ethical analysis in HTA and clarify the reasons for such diversity. Our systematic review of HTA literature pertaining to the barriers to the integration of ethics in HTA identified nine ethical approaches: Principlism, Casuistry, Coherence Analysis, Wide Reflective Equilibrium, Axiology, the Socratic approach, the Triangular model, Constructive Technology Assessment and Social Shaping of Technology. Citations pertaining to each approach were extracted and categorized according to three constitutive components of ethical argumentation established in a previous research evaluating nanotechnologies: i) the disciplinary foundation that grounds the validity of the ethical evaluation, ii) the characteristics of such evaluation, iii) the operational process involved in applying it to a particular case (i.e., its practical reasoning). This comparison shows that, 1) the difference between these approaches rests primarily on their disciplinary foundation (rooted in philosophy, philosophy/theology, or
\end{abstract}


sociology), 2) their complexity can be observed in the distinct characteristics of ethical evaluation deriving from their differing disciplinary foundation, and 3) although four different types of operationalization procedure were identified, little information was available in regards to the practical reasoning associated with these approaches.

\section{Keywords}

Health Technology Assessment, HTA, Ethics, Methods of Ethical Analysis, Principlism, Casuistry, Wide Reflective Equilibrium, Axiology, Triangular Model, Constructive Technology Assessment

\section{Background}

For any new technological development, the question of ethical issues is raised. After the development of genomics and nanotechnology, artificial intelligence is now investigated for its impacts and the ethical issues it involves. If naming these issues is the first operation, the ethical evaluation is another matter that challenges applied philosophy, namely applied ethics. Different organizations such as the Nuffield Council on Bioethics in the UK, the Comité national d'éthique in France or the Commission d'éthique en science et technologie in Québec, Canada address this task of applying philosophical inquiry in concrete social decision making. Health Technology Assessment organisations throughout the world also face the same philosophical challenge. The EUnetHTA definition clearly states that: "Health technology assessment is a multidisciplinary process that summarises information about the medical, social, economic and ethical issues related to the use of a health technology in a systematic, transparent, unbiased, robust manner. Its aim is to inform the formulation of safe, effective, health policies that are patient focused and seek to achieve best value" (WHO, 2019).

Health Technology Assessment (HTA) has been entwined with ethics since its beginnings, because its final goal: global public health can only be attained through "sound" clinical practice (WHO-HTA, 2017). Although ethics is explicitly recognized as a component of the HTA process, its integration through an ethical analysis in the HTA procedure has proven difficult to implement. Numerous articles published by Björn Hofmann since 2005 have already called for a better integration of ethical analysis in HTA (Hofmann, 2005a, 2005b, 2008, 2013, 2014).

The reasons for which there is difficulty of integrating ethics in HTA have been investigated for some time. HTA assessments are basically structured to first assess safety and effectiveness of a technology and analyse its' cost-effectiveness in order to decide on its impact on the health care system. Each of the analysis is based on the objective nature of the systematic review process, which is conducted according to recognized and standardized methods. Ethics, in this scientific context, is seen as "subjective" in comparison to the "objectivity" of scientific methods. Revisiting the fact/value dichotomy (Legault et al., 2018) is the first chal- 
lenge to tackle in philosophical analysis in order to overcome the fundamental barrier for the integration of ethics in HTA. Articles by Assasi et al. (Assasi et al., 2014, 2015, 2016) have identified and summarized a number of other barriers, two of which originate from the very nature of ethical analysis itself. The first is the diversity in the kinds of ethical analysis proposed and their complexity; the second is in the difficulty of applying ethical analysis in such a way as to obtain tangible results (Assasi et al., 2015). This was confirmed by our recent systematic review of the literature (Bellemare et al., 2018), where the citation "no settled proceedings for ethical analysis" (reported 28 times) appears to be deemed a sufficient reason for conducting HTA without including ethical analysis.

Recognizing the need to integrate ethics into their own HTA processes, as well as wishing to see HTA fulfill its ultimate goal of informed decision making, some members (SKB, CAB, and PD) of the local HTA unit of the Centre intégré universitaire de santé et services sociaux de l'Estrie-Centre hospitalier universitaire de Sherbrooke (CIUSSS de l'Estrie-CHUS) tackled this problem. In so doing, they found themselves confronted not only by the complexity of the different kinds of ethical analysis proposed in the literature, but also by the absence of a systematic and operational approach. Their eagerness to solve this problem prompted the initiation of the interdisciplinary research project intrinsic to the paper entitled "Theoretical and practical operationalization of the integration of ethics into the process of Health Technology Assessment (HTA)" (IRSC-CIHR grant no. 142187). The present paper aims to identify the theoretical and practical differences between the approaches underpinning ethical analysis in HTA and clarify the reasons of such diversity. The question raised is two-fold: is the diversity of ethical analysis, compared to the standardized scientific methods for systematic reviews, a sufficient reason to consider it inadequate for HTA? If not, how can applied philosophy bring pertinent results for HTA?

\section{Theoretical Basis of the Comparison and Methodology}

At the beginning of our research a systematic review (Bellemare et al., 2018) of the barriers on the integration of ethics in HTA was undertaken. We analysed the quotes referring to ethical analysis, values, value-judgments and philosophy that were extracted and compiled from the databank used for our systematic review on ethics in HTA. This review surveyed several databanks, until November 21, 2016, using general key words: "ethic," "technology assessment," and "HTA". Nine ethical approaches were identified, and all relevant quotes were then gathered. The nine approaches are: Principlism, Casuistry, Coherence Analysis (CA), Wide Reflective Equilibrium (WRE), Axiology, the Socratic approach, the Triangular model, Constructive Technology Assessment (CTA) and Social Shaping of Technology (SST). Although some of the authors covered in the review deem that there is no difference between CA and WRE nor between Axiology and the Socratic approach, they are treated as distinct approaches in the current paper for the sake of clarity. 
A comparison between the nine approaches required a rigorous grid that can systematically treat variables between them. In our previous work on the ethical implications in nanotechnology, we were confronted with the difficulty of comparing different ethical perspectives concerning the use of nanotechnology in the case of transhumanism (Béland et al., 2011; Legault et al., 2013; Patenaude et al., 2011). From a philosophy of language perspective, ethic, moral and law are all normative languages whose aim is to guide conduct. A normative language has three components: i) the normative statement, ii) the practical reasoning that applies the normative statement to a particular case, and iii) the foundation level where the normative statement is grounded in a philosophical perspective.

All citations relevant to these nine approaches were then analyzed and categorized using the following grid: i) the disciplinary foundation that grounds the validity of the ethical evaluation, ii) the characteristics of the ethical evaluation, and iii) the operational process involved in applying the ethical evaluation to a particular case (i.e., its practical reasoning). After a distinctive classification by the philosophers in the research group, a consensus was reached on all categorized citations. Reference works gathered on the nine approaches were also examined in order to document any conflicting perceptions encountered in the literature review with respect to each approach. Finally, these results were ratified following a systematic interdisciplinary dialogue within our InternE ${ }^{3} \mathrm{LS}^{1}$ research group, which includes three HTA practitioners.

\section{Results of the Analysis}

The nine ethical approaches identified ${ }^{2}$ were grouped in one of two categories: 1 ) under the social-science or humanities disciplines that define their respective concepts of ethics; or 2) under the methods involved in the process of identifying ethical issues. As shown in Table 1, foundational discipline is philosophy in the case of six of the approaches is philosophy (i.e. Axiology, Casuistry, CA, Principlism, WRE, and the Socratic approach); both theology and philosophy underlie the Triangular model; and sociology underlies CTA and SST. Clarifying

Table 1. Disciplinary foundation of the ethical evaluation.

\begin{tabular}{cc}
\hline Disciplinary foundation of the ethical evaluation & Approach \\
\hline Sociology & $\begin{array}{c}\text { Constructive Technological Assessment } \\
\text { Social Shaping of Technology }\end{array}$ \\
Philosophy/Theology (substantial ethics) & Triangular model \\
Philosophy (non-substantial ethics) & Axiology \\
& Casuistry \\
& Coherence analysis \\
& Principlism \\
Socratic approach \\
\end{tabular}

${ }^{1}$ http://interne3ls.3it.usherbrooke.ca/.

${ }^{2}$ To give examples explaining each of the approaches covered in this study so as to outline them is beyond the scope of this article. 
the concept of ethics at the disciplinary level from the very beginning therefore helps us to understand the nature of each ethical evaluation and the practical reasoning required to apply such an ethical evaluation to a specific technology.

\subsection{Philosophy}

The six approaches with philosophy as their foundational discipline have one common denominator: their denial of the possibility of finding a universal moral truth. The way Lysdahl et al. characterize the coherentist dimension of WRE is transferable to all the other five approaches: "Coherentist, here, is used in contrast to foundational approaches, which assume that there are certain undisputable basic principles from which moral judgments can be derived" (Lysdahl et al., 2016). The absence of a universal moral truth means that ethical analysis cannot be grounded on one - universally shared - world view. Each approach must therefore identify the reasons that justify its own acceptability. Since some approaches concentrate more on the foundational level than on the evaluative or operational levels, we first present here the approaches that are more general. Certain approaches have also been grouped and reported together because of their similarities. These are CA and WRE, Axiology and the Socratic approach, and Principlism and Casuistry.

1) Coherence Analysis (CA) and Wide Reflective Equilibrium (WRE)

Coherence Analysis (CA) and Wide Reflective Equilibrium (WRE) are viewed by some authors as indistinguishable, since WRE is by definition a coherentist model (Lysdahl et al., 2016). While we acknowledge that this claim is valid at the foundational level, since both approaches cope with the absence of truth in morals by a "test of consistency" (Saarni et al., 2008), it is not so at the ethical-evaluation level. In fact, only the coherence between moral judgments, moral principles and background theory justify results, because different ethical analyses can be provided for a single technology (Daniels \& van der Wilt, 2016). We therefore accounted for each of these approaches separately, based on the differences between CA and WRE at the ethical-evaluation level.

In CA, ethics is considered to be a complex network of ethical components, namely "theories, principles and value judgments," (Assasi et al., 2014) that are logically interdependent (Saarni et al., 2008). Thus, any flaw in the coherence of the ethical reasoning may disqualify the moral reasoning from a philosophical point of view.

A CA-based ethical evaluation can only show that certain sets of arguments are non-logically consistent. It cannot conclude that one set of arguments is better than the other. CA thus constitutes a descriptive approach to ethics: "It is a procedural, pragmatic approach, i.e. it describes a procedure of approaching moral issues without claims of providing direct answers on 'right or wrong"' (European Network for Health Technology Assessment (EUnetHTA), 2016). An ethical analysis whose aim is to determine the logical consistency of moral arguments can yield important results in order to support the decision-makers' 
justification of their final choice about the use or not of a specific technology. This kind of analysis helps in discarding illogical ethical argumentation and clarifying the choice between competing moral standpoints about the subject of analysis.

In HTA, CA can only proceed from a given moral reasoning on a particular use of a technology in health. Of course, the starting point may be a value judgment that carries implicit principles and ethical theories. In such a case, CA will help make the principles and theories involved more explicit and will examine their logical coherence. Since the main focus of CA is on ethical reasoning, this approach is best suited to the analysis of disputed ethical arguments on specific technologies in a social debate. WRE is concerned essentially with moral reasoning because of its coherentist approach. Its main difference from CA lies in the final goal of the analysis: WRE is concerned with "which moral principles are at stake" (Hofmann et al., 2015). Thus in contrast to a "descriptive approach" like that of CA, the WRE approach is reflective and is based on Rawls' theory of justice (1971) (Lysdahl et al., 2016), in which reflection on moral reasoning is conducted under "a 'veil of ignorance' (i.e. imagining we do not know which position we would have in the society that our decisions concern) to try to be as impartial as possible. This might entail that some of our primary considered judgments have to be adjusted." (European Network for Health Technology Assessment (EUnetHTA), 2016).

The starting point of WRE's ethical evaluation is "based on a society's normative framework, expectations, and objectives” (Hofmann, 2014). Its ethical analysis aims at a moral justification that is coherent for all of its components (value judgment, principles, and background theory) and is based on the primary value judgments encountered in a society. WRE does not take social value judgments for granted as the reference for moral justification, because the reflective approach of the "veil of ignorance" reduces the bias of a particular interest in order to achieve what is best for any person in society.

This approach is best operationalized in HTA by using a participatory process, since it is anchored in society's normative frameworks and in the diverse value judgments on health choices to be found within a society (Bombard et al., 2011). According to Assasi et al. (Assasi et al., 2014), the WRE approach aims to reach a balanced agreement among stakeholders on what is best by deploying a coherentist approach to moral reasoning and relying on the adoption of the "veil of ignorance" in the taking of a moral perspective.

\section{2) Axiology and the Socratic Approach}

Axiology and the Socratic approach were often deemed to be identical in the HTA literature we reviewed. Axiology is the more general of the two; the Socratic approach can be viewed as a specific way of conducting axiological ethical analysis.

The nature of the philosophical concept of ethics that underlies an axiological approach was not clearly identified in the quotes we analyzed. In traditional philosophy, there is no distinction between ethics and morals. This contrasts 
with contemporary applied ethics, where norms and values are recognized as distinct forms of normative evaluation (Legault, 2014). Value judgment is the core concept of ethics in Axiology. The link between facts, values, and value judgment appears in the justification for accepting or rejecting a technology (Hofmann, 2005a). Within this perspective, value judgments are intrinsically related to decision-making where facts concerning a technology are to be evaluated. This is why value judgments are the foundation of the final decision. According to Hofmann, this is why value judgments are more closely related to appraisal than to assessment. In fact, "As the decision process clearly is an evaluative task, the value analysis is a fruitful way to make HTA more feasible for health policy. Hence, the axiological approach links the assessment closer to the appraisal, and, hopefully, is able to connect the 'two cultures"' (Hofmann, 2005a).

As with CA and WRE, ethical analysis in Axiology can be either descriptive or evaluative. When it is descriptive, its main goal is to map ethical issues. Generally, an ethical issue is defined as "A conflict of right (ethical) or wrong (unethical) or situation forcing alternatives on an entity seeking ethical behavior" (Campbell Black, 2017). Is the integration (or not) of a given technology into a healthcare system ethical? In order to be able to answer this question, a descriptive ethical analysis can help identify the ethical issues related to the use of a specific technology in a healthcare system and explain why there seems to be a conflict. In contrast, an evaluative ethical analysis would seek to do more than identify the ethical issues: it would propose an evaluation of the situation. A conclusion could then be reached regarding the ethical acceptability of the new health technology. In our literature review, we found no references to the development of evaluative analysis for health technology via a theoretical approach based on value judgment.

The operational process for an Axiology-based ethical analysis cannot be reported here as a distinct process since, in the HTA literature we reviewed, this approach was mostly associated with the Socratic approach. An evaluative ethical analysis in HTA would, however, require a clarification of the concept of value judgment and of how that concept can be systematically applied in HTA.

The philosopher Socrates initiated a process of philosophical inquiry based on dialogue, in which the questions asked were key to the inquiry. Understanding the question and trying to answer it implies a reflective process, which develops awareness of the different dimensions of a given situation. This aspect of Socrates' way of conducting a dialogue characterizes the use of the Socratic approach in HTA. "The calling of the Socratic approach is 'to ask questions, not to give answers,' to paraphrase the poet Henrik Ibsen'" (Hofmann, 2005a). The final goal of a philosophical theory that asks questions instead of answering them is to develop awareness and critical thinking (Hofmann, 2008). The Socratic approach is not a "moral theory", nor a "method" or a "procedure" (Hofmann, 2005b). Rather, it proposes a "checklist" of thirty-three questions that help identify ethical issues raised by a given health technology. The diverse character of the checklist is designed to incorporate "several methods in ethics, such as 
deontology, utilitarianism, principlism, casuistry, and virtue ethics" (Hofmann et al., 2014).

The Socratic approach does not offer an ethical evaluation of a technology, as it does not seek to give answers. But, because it self-identifies as related to Axiology, values and value judgments have an important function in its ethical perspective. An analysis of the first five questions proposed by Hofmann helps illustrate its evaluative function (Hofmann, 2005b). In addressing the question of consequences, Question 1: "What are the morally relevant consequences of the implementation of the technology?" implicitly requires an impact analysis of a technology's implementation for different stakeholders. But, to take due account of the words "morally relevant consequences," one must identify how a consequence is linked to a specific value. Similarly, to answer Question 2: "Does the implementation or use of the technology challenge patient autonomy?", one must inquire into consequences that might conflict with the value of patient autonomy. The same procedure is implied in the three remaining questions of the first five: Question 3: "Does the technology in any way violate or interfere with basic human rights?"; Question 4: "Does the technology challenge human integrity?”; Question 5: "Does the technology challenge human dignity?” (Hofmann, 2005b).

There seems to be two different ways to operationalize the Socratic approach in the HTA literature. One is proposed by Saarni et al., who demonstrate how the mapping of ethical issues involved in the implementation of a technology can be done in HTA by first identifying the moral challenges related to a technology (using Hofmann's questions) and then performing a systematic literature search based on that former identification (Saarni et al., 2011).

The thirty-three questions proposed by Hofmann (Hofmann, 2005b) were not, however, clearly oriented this way at the outset. In our view, the purpose of these questions is to raise awareness and cultivate critical thinking in regard to the values already embedded in the HTA process. By doing so, such critical thinking could influence the process of HTA and make it more transparent. Assasi et al. seem to confirm this interpretation when they identify the focus of the Socratic approach as being part of the "process of HTA," rather than viewing it as an ethical inquiry per se (Assasi et al., 2016).

\section{3) Principlism and Casuistry}

Principlism and Casuistry are two evaluative ethical-analysis approaches developed in the field of applied ethics. Like CA and WRE, these two approaches reject the idea of universal moral norms that yield true answers following a moral evaluation. In contrast to CA and WRE, however, both approaches also reject the emotionalist theory of ethics, which considers all moral and value judgments to be devoid of rationality and express an emotional state that constitutes a response to a situation. In CA and WRE, the place for reason in ethics is adjacent to the logical dimension of ethical argumentation. In contrast, in Principlism and Casuistry, ethics is deployed in the practical reasoning involved in the moral 
evaluation of a situation. Each offers a specific way of contemplating the moral evaluation of a technology.

Principlism is a version of Situational Ethics, initially developed by Joseph Fletcher (Fletcher, 1966), which argues that a moral evaluation is always carried out in a particular decision-making context. Situational Ethics focuses on the relationship between people in concrete settings, which entails that the decisions one takes have an impact on other individuals. Sharing the moral reasons for a decision with stakeholders is therefore one way to bring about better ethical practices.

Principlism was first developed in the context of medical ethics, in response to the critique directed at medical paternalism, which imposed decisions by a medical authority on the patient. In this medical context, autonomy becomes a guiding principle for the ethics of medical research and for the forging of medical relationships based on free and informed consent. Since the formulation of the Hippocratic Oath, non-maleficence and beneficence have been the two main guiding principles of medical practice. In today's society, where medical practice is incorporated into welfare systems, the question of justice also arises: how are medical resources shared in society? According to many authors, the four principles are based on a "common morality" (Hofmann, 2014; Park et al., 2016; Saarni et al., 2008) and reflect society's professional expectations.

Lysdahl et al. summarized this approach clearly: "The most frequently used form of Principlism (i.e. to apply principles to solve moral problems) addresses the four basic ethical principles: respect for autonomy, non-maleficence, beneficence and justice" (Beauchamp \& Childress 2001 as quoted in (Lysdahl et al., (2016)). The end result then takes shape of a recommendation formulated in line with a solution to a moral problem.

In the HTA literature, the description of the four ethical principles is best described by Saarni et al.: "Principlists propose that the analysis of ethical issues in biomedicine can be conducted with recourse to four moral principles: respect for autonomy (with a focus on human free will and agency); beneficence (the obligation to do good for others); non-malfeasance (the minimization of harm to others); and justice (the distribution of benefits and burdens)" (Saarni et al., 2011). However, there is no hierarchy of principles in Principlism, e.g. Autonomy, is not the first principle. All four principles are morally equivalent and stand on the same level. Yet in a particular situation, accepting a specific technology might comply with certain principles but not with others. Under such circumstances, the Principlist's ethical analysis must ultimately find a solution in a case of conflict and weigh the principles against each other (Lysdahl et al., 2016).

Given that the Principlist approach originated in the field of medical ethics, it is not surprising to find that its concepts are those most frequently invoked in the HTA literature [10] When this approach is applied in the context of HTA, the obligation to the "do no harm-principle" is the main focus of the safety analysis and the principle of beneficence that of the analysis of clinical effectiveness. 
Respect for the principle of justice will subsequently inform the economic analysis.

Since the four obligations of Principlism are rather abstract, they must be adapted to the practicality of the technology to be evaluated. According to Saarni et al., "In practice, the principles are usually applied to the ethical issue or case under discussion in turn [...]" (Saarni et al., 2011). Little information was found in our systematic review about how the implementation of a given technology complies or not with each principle. For example, a technology can have many impacts on patients, professionals and organizational settings, as well as on society. To gauge compliance or non-compliance of the implementation with the four principles requires the existence of a procedure to determine the impacts to be considered. No information was found concerning any such procedure.

Once an ethical evaluation has been clearly established for each principle, the next step consists of integrating the four evaluations in a final conclusion. Various suggestions have been made for how this can be done. One recommends using a coherentist approach to produce a final proposal for a way of integrating a technology that will respect all four obligations (Saarni et al., 2011). This is theoretically possible, because respecting norms involves a binary analysis: "respects"/“does not respect." If the implementation of a technology fulfills at least one of the obligations, it may be possible to find ways of implementation that promote compliance with the other three. A second suggestion is to prioritize the four obligations and justify why certain infringements on one or either of them may be tolerated (Saarni et al., 2011).

The complexity of the principlist's ethical evaluation requires ethical expertise and this approach is thus not currently being integrated into assessment processes. This need for expertise is why Principlism is considered a "top-down manner" of integrating ethics into HTA (Assasi et al., 2014; Braunack-Mayer, 2006; Hofmann et al., 2015). With this approach, ethical analysis becomes an "add-on" to the assessment (Saarni et al., 2011).

Casuistry has a long history in the world of philosophy (Lysdahl et al., 2016). It formed the heart of applied theology in the Middle Ages; but in the seventeenth century, it came under severe criticism by members of the Jansenist movement, especially the mathematician and philosopher Blaise Pascal. Casuistry was practiced by the Catholic Church in counselling for those who seeked spiritual guidance to make the right choice in a particular situation. Applying the general commandments of God and the Church to a particular case requires a moral reasoning in which facts are confronted with principles in order to find a right answer. But the same attitude towards a given case may be viewed as wrong by one spiritual guide and right by another. It is widely recognized that nothing is more distant from mathematical deductive reasoning than Casuistry. No wonder Blaise Pascal, from his deductivist standpoint, criticized the dialectical reasoning based on facts and norms inherent in Casuistry. He viewed its use as evidence of the relaxed morality of the Jesuit order. 
It is not coincidental that Casuistry was rehabilitated within the field of applied ethics (Jonsen \& Toulmin, 1988). For many individuals, moral reasoning is a deductive process in which moral principles, like those of mathematics, easily provide the correct answer about what is right and what is wrong. However, applied ethics proposes a bottom-up approach to ethics, which contrasts with the deductive approach of traditional morals found in theology and philosophy (Saarni et al., 2011).

Casuistry formulates an explicit moral judgment on a particular case (Hofmann, 2005b). Being focused on the decisions people take in their everyday lives, Casuistry guides moral reasoning in the context of family life, professional life and community living. Since there are no universal moral norms, the starting point of Casuistry consists of maxims or rules embedded in personal, social, and legal norms (Reuzel et al., 1999). Because there are no a priori maxims or rules to be considered in Casuistry, it is characterized solely by its normative approach. The final moral judgment identifies which obligation will govern the case under examination (Reuzel et al., 1999).

Different interpretations of Casuistry were identified in the quotes analyzed; these implied conflicting perspectives on its actual reasoning process. According to some authors, in casuistry, the moral reasoning process consists in identifying paradigmatic cases for which generally accepted solutions already exist, thus allowing for a determination of the obligation at issue by analogy (Assasi et al., 2014; European Network for Health Technology Assessment (EUnetHTA), 2016; Lysdahl et al., 2016). In this version of Casuistry, the moral reasoning process seems to rest on compliance with a recognized principle.

Another interpretation of Casuistry was identified, one that leaves more room for critical thinking in moral reasoning than what the strict compliance does. As was the case in the first interpretation, the moral reasoning process starts with identifying how similar cases were solved and on what moral grounds. However, at the level of the application to the case, this second interpretation of Casuistry operates by a dialectical conversation between facts and norms. Reuzel et al. identify one way to perform such critical thinking: "General maxims cannot be applied to, but should be made meaningful in these case. For example, a maxim like "murder is wrong" cannot simply be applied to the case of a woman who has an abortion for medical reasons. Rather, it should be asked what it means to say that, in this case, abortion on medical indication is, or is not, murderous. The question, then, is: what makes one case different from another? If we accept a certain case, say, the case of a child being killed by a rather overwrought parent, to be a case of murder, then what makes this case different from the case of abortion on medical indication? In other words, casuistry involves clarifying the ethical concepts used through comparing different cases with each other" (Reuzel et al., 1999).

The complexity of ethical evaluation in Casuistry explains why it requires experts in ethics (Bombard et al., 2011). As with Principlism, in Casuistry the integra- 
tion of ethics is seen as an add-on to the regular HTA process (Assasi et al., 2014).

\subsection{Theology and Philosophy}

The Triangular model is grounded on a cognitivist moral perspective based on the work of the theologian and philosopher Thomas Aquinas, which integrates Aristotle's ethics into a theological perspective (Sacchini et al., 2009) and maintains that it is possible to gain knowledge of what is true in morals just as it is possible for empirical science to gain knowledge about the world (European Network for Health Technology Assessment (EUnetHTA), 2016). At the foundational level, the Triangular model is in opposition to the six philosophical approaches analyzed above, since it takes a substantial view of morals, whereas the others take a non-substantial one. In other words, according to this approach, it is possible to acknowledge undisputed moral principles from which moral judgments can be derived in order to be applied (Lysdahl et al., 2016). Although this model proposes a cognitivist approach, the literature does not specify what such an approach could consist of nor how it leads to a "substantial conception of human person" (European Network for Health Technology Assessment (EUnetHTA), 2016).

The Triangular model is viewed as a person-centered approach because, under it, the concept of a human person is upheld as a "reference-value in reality" (Sacchini et al., 2009). This fundamental concept of a human person is the basis of all the ethical judgments that can be made in this type of ethical evaluation.

Four principles have been identified for the purpose of ethical evaluation based on the concept of a human person: "a. the defence of human physical life; b. the contextual exercise of freedom and responsibility within the decision-making process; $c$. the safeguard of the therapeutic principle, according to which the human person has to be treated as a whole of body and soul; $d$. the principles of sociality and subsidiarity, for which public and private authorities are called to help all persons in need" (Sacchini et al., 2009). These principles are intended to clarify how values such as that of human life, integrity, and dignity can be applied in the evaluation process.

The end point of the ethical evaluation is also normative in this case and consists of identifying the "practical choices that should be made" (European Network for Health Technology Assessment (EUnetHTA), 2016).

The EUnetHTA Core Model describes the three steps of the Triangular model (European Network for Health Technology Assessment (EUnetHTA), 2016). The first step, data collection, requires "an in depth study of all factual data concerning the technology" (Sacchini et al., 2009). A clear picture of the technology at issue, including its components, origin, purpose and consequences, is the starting point for this kind of ethical evaluation. The second step is the ethical/anthropological analysis, in which the four evaluation principles are applied to the case. Though this is not explicitly stated, it may be assumed that the analysis consists of evaluating the consequences of the technology (i.e., data collec- 
tion) for the human being. The third step is the normative level: here the ethi$\mathrm{cal} /$ anthropological analysis guides the final ethical evaluation that normatively determines a given practical choice.

Though no mention is made in the literature regarding the Triangular model of a need to resort to ethical experts, it may be assumed, given the substantial-ethics model it is based on, that under this approach an ethical evaluation could not be conducted without the support of experts in the field.

\subsection{Sociology}

SST and CTA are two approaches focused on Technological Assessment and its link with the HTA process. Both adopt a perspective informed by Science \& Technology Studies. They propose that the HTA process shifts from the evaluation of social impacts towards a social perspective, in which the development and implementation of technology in society are inherently normative (Hofmann et al., 2015; Lehoux \& Williams-Jones, 2007). Each approach proposes a different way to articulate HTA with Technology Assessment.

From a sociological point of view, a society imposes on its members different norms and values embedded in its culture. These norms can be explicit in the laws of a nation or be implicit in the "mores" i.e., the binding customs of society's behavioral expectations. Both laws and mores develop within the social dynamics of a society; technology and society are thus considered to be "co-constructions or co-evolutions" (Reuzel et al., 2004). Sociology hence considers ethics and norms as socially determined and relative to the culture in place.

In contrast to Principlism, Casuistry and the Triangular model, SST and CTA do not seem to propose the ethical evaluation of a technology. Their approaches are identified as being focused on the HTA process rather than on ethical analysis (see Table 2 in Assasi et al. 2016 (Assasi et al., (2016)). There is nevertheless an implicit normative stance in SST and CTA, however, because they support the view that "technology can be best managed by society" (European Network for Health Technology Assessment (EUnetHTA), 2016); i.e., ethical analysis is warranted only in certain social contexts (European Network for Health Technology Assessment (EUnetHTA), 2016).

The SST approach provides contextual information to HTA that will help avoid the pitfall of "The inadequacy of evaluating a technology without considering the local social environment" (European Network for Health Technology Assessment (EUnetHTA), 2016). This approach offers a better understanding of the social dynamics that govern the development of technology (Reuzel et al., 2004). In fact, it promotes a better assessment of the "role, merit and value of a technology" (Hofmann et al., 2015).

CTA proposes a participatory approach to identifying "possible social and ethical implications of health care technology" (Liberati et al., 1997). The CTA process takes the form of a dialogue between stakeholders in order to arrive at an understanding of everyone's claims and concerns and the documenting of these 
claims and concerns to see whether agreements can be reached and, if so, on what basis (Liberati et al., 1997).

\section{Discussion}

The differences among the nine ethical approaches identified in the HTA literature derive primarily on the disciplinary foundation(s) of their ethical evaluations, that is, on whether the disciplinary framework is provided by sociology, philosophy/theology or philosophy, as shown in Table 1.

In any discipline of the humanities and the social sciences, methodological assumptions exist about what ethics is considered to be. From a sociological perspective, ethics is the product of society and social norms and values constitute the very basis of ethical evaluation and ethical reasoning. Ethics is therefore essentially relative to a social culture in CTA and SST. The Triangular model's assumption is that the knowledge of what ought to be is given by a specific philosophical approach integrated into a specific theological perspective. Substantial ethics presumes the universality of moral matters. The disciplinary foundation of six of the approaches identified is based on non-substantial ethics. This perspective in philosophy assumes, neither, that ethics is relative to a society's culture nor grounded on ethical truths. It assumes, rather, that there is a place for the application of reason in ethics, with the adoption of a critical standpoint allowing for better decision making and consequent benefits to society.

The complexity of ethical analysis is evident in the diversity of characteristics of ethical evaluations, as shown in Table 2.

For sociology, the mores of a society, as revealed in the social processes regulating the development and implementation of technology, serve as the basis for ethical evaluation. The social processes involved tend towards the social acceptance of a technology; accordingly, the social impact of a technology should be nuanced by the social acceptance process mentioned above. In the Triangular model, evaluation involves substantial moral norms. A moral norm stipulates what ought to be and so indicates the difference between right and wrong. A

Table 2. Characteristics of the ethical evaluation.

\begin{tabular}{cc}
\hline Characteristics of the ethical evaluation & Approach \\
\hline Social processes (mores) & $\begin{array}{c}\text { Constructive Technological Assessment } \\
\text { Social Shaping of Technology }\end{array}$ \\
Substantial moral norms & Triangular model \\
Common morality (shared norms in society) & Coherence Analysis \\
Pommon sense (shared maxims) & Principlism \\
Maieutic (question based: fact/values) & Casuistry \\
Values & Socratic approach \\
\end{tabular}


normative evaluation is also at the core of three other philosophical approaches: Principlism, CA, and WRE, which evaluate technology by applying shared norms in society. Common morality is the starting point for ethical evaluations in these normative approaches. Casuistry is slightly different, since its starting point is based on shared maxims. Maxims like, "Do unto others as you would have them do unto you," are deemed to provide moral guidance grounded in "common sense." In philosophy, some consider that we cannot have a conceptual knowledge of what is right or wrong, but that we all have a moral faculty called "common sense" that guides our evaluation of conduct. The Socratic approach, in proposing no more than an ethical questioning about the implications of adopting a technology, does not aim at a morally normative evaluation. Under its process of acting as a "midwife" to knowledge, that is, of eliciting knowledge, questions are designed to inquire into both facts and values and are aimed at a better evaluation by all of what is involved in the ethical complexity of HTA. Axiology, though it can be considered independent of the Socratic approach, has not been explicitly so identified. Yet many references to values and value judgments in the HTA literature indicate that there implicitly exists, in HTA, a basis for a type of value-based ethical evaluation that differs from normative ethical evaluation.

At the operational level, two somewhat related dimensions were considered. The first is the practical reasoning involved in the operationalization of ethical analysis in HTA, as shown in Table 3. The second is the necessity or not of having an ethical expert carry out ethical analysis. Four different types of ethical evaluation in HTA have been identified, each of which operating through a specific practical reasoning procedure.

Table 3. Operational process-practical reasoning.

\begin{tabular}{cc}
\hline Operational process: Practical reasoning & Approach \\
\hline Social acceptance procedure & Constructive Technological Assessment \\
& Social Shaping of Technology
\end{tabular}

Applying general norms to a specific case.

a) identifying the facts pertaining to the case

b) identifying the norms applicable to the case

c) resolving the conflict between norms (when present)

d) establishing the conformity or non-conformity (actions/norms)

e) justifying the final judgment on conformity

Applying value judgments to a specific case: question-based

\author{
Casuistry \\ Coherence analysis \\ Principlism \\ Triangular model \\ Wide Reflective Equilibrium \\ Socratic approach
}

Applying value judgments to a specific case: value analysis
a) identifying the facts pertaining to the case
b) specifying the value judgments applying to the facts
c) identifying the conflict between value judgments
d) prioritizing the value judgments
e) justifying the final value judgment

Axiology 
CTA proposes an approach based on interaction with different stakeholders in order to clearly identify the ethical issues involved in the implementation of a technology and the possible conflicts between their respective ethical evaluations. This interactive approach is grounded on a dialogue between stakeholders and focuses on the search for common bases for the ethical evaluation; if such common bases are not found, it then focuses on arriving at an understanding of the ethical conflict between the different points of view. The resulting picture will show where social acceptance is reachable and where it is not. SST does not propose a specific procedure for HTA but emphasizes the fact that technology itself, being socially accepted in society, should not be subject to an ethical evaluation in the context of HTA.

Five of the ethical-evaluation approaches in philosophy and theology are norm based. The process of practical reasoning in norm-based ethics consists of a complex procedure that must bring together facts and norms. The facts being the starting point, one may ask: what are the facts that are open to moral evaluation? The identification of the facts involved and of the norms applicable to these facts can be rather complex to carry out. For instance, if autonomy is taken as a norm, which facts can be considered as a possible breach of autonomy? Furthermore, different facts may be concerned with different norms. Conflicts of norms, for example, between autonomy and justice, must be resolved. Of course, when these philosophical approaches give priority to a value, as in the Triangular model for example, the conflict is quickly resolved. Basically, norm-based practical reasoning is a reasoning that searches for compliance with the norm. The facts of a case may involve a specific norm, but this does not mean there is a breach of compliance. The moral reasoning process must therefore specify why, in light of the facts, there is (or not) such a breach. Although the validity of an ethical evaluation rests on the practical reasoning that operationalizes it, there is too often insufficient precision concerning the specifics of these procedures in the HTA literature.

The Socratic approach is a question-based approach centered on the value judgments implied in the HTA process. This approach does not propose an ethical evaluation of HTA, as a normative or axiological approach would. The aim is rather to guide reflection by HTA evaluators or stakeholders regarding the ethical issues that may be involved in the evaluation of a technology. General questions, like general norms, must be applied to the facts of a given case in order to guide reflection. Little information has been provided about how to apply these general questions to a given case.

The HTA literature indicates that a value-based ethical evaluation is possible but gives little indication as to how such an evaluation could be operationalized. An Axiological approach to Technology Assessment as conducted in the field of nanotechnologies (Patenaude et al., 2015) can help clarify how HTA could integrate value judgments in a more systematic manner. Value-based ethics, like norm-based ethics, must bring together facts and values. Since the starting point 
is the identification of the facts pertinent to a given case, the practical reasoning process of value-based ethics relates to the impact of the implementation of a technology. An impact analysis must thus cover all the possible impacts for all the different stakeholders. It is precisely the nature of a given impact that identifies the issue at stake. To make a value judgment on an impact, one needs to identify the value of reference and formulate a judgment on how the impacts identified will affect that value, whether positively or negatively. Since Technology Assessment in health care often reveals complex situations, the impact analysis may come to show a positive outcome for some values but a negative one for others. Therefore, a full picture of the conflicting value judgments is needed. The next step would then be to prioritize the value judgments in order to justify the final value judgment on the technology.

Our results indicate that the complexity of ethical analysis may explain why the integration of ethics requires ethical expertise. However, a question remains: must the final ethical analysis be necessarily an add-on to the "classical HTA report"?

\section{Conclusion}

Integrating ethics in HTA requires answers to two questions capturing the essential barriers that challenge it. The first, comparing to the standardized methods of systematic review, is the diversity of ethical analysis a sufficient reason to by-pass ethical evaluation? Humanities and social sciences do not have, like natural sciences do, settled proceedings, which can explain the diversity in the possible analysis. The fact that there are nine approaches for ethical analysis in HTA is not surprising, but how can HTA agencies cope with so much diversity? Is choosing an approach instead of another just a question of social preference or should it be rationally justified? Since HTA is a rational process, all the choices involved in the adopted ethical evaluation should be made explicit. Why choose between a norm-based approach or a value-based approach in ethics? The reasons of this choice can only be identified at the foundational stage where the philosophical perspective is made explicit.

The second question to address is: How can applied philosophy attain pertinent results for HTA? Ethical evaluations must be carried out systematically throughout the operational process of an HTA if it is to provide information that is useful to decision makers. According to our systematic review, the "operational process" aspect related to ethical evaluation has not been clearly spelled out so far (Bellemare et al., 2018). Little information was traced in regard to the different steps of value based and norm based practical reasoning. In our grid, we identified different procedures that, if taken into account, could provide pertinent results for the decision-maker. Practical reasoning in norm-based ethics is similar to the legal reasoning established in the judicial process where the facts retrieved show that the action considered is or is not in conformity with the specified norm. Value-based practical reasoning not only identifies the value judgments attributed to each impacts of a technology but also establishes the final 
value judgment between all conflicting value judgments. The lack of clarification of the practical reasoning involved in the nine approaches identified in HTA may explain why the ethical analysis seemed subjective to the ethical expert consulted.

In theoretical philosophy the choice between different approaches is made at the foundational level. The arguments presented establish why an approach seems more justified than another. In applied philosophy this choice is more pragmatic. When assessing a technology, ethical evaluation is confronted with a multiplicity of positive and negative impacts on the different stakeholders. At this pragmatic level, the question is: which normative language is best suited to evaluate these conflicting impacts. Having to make a choice between the approaches stems first from the practical reasoning potentialities and, depending on the technology involved, certain approaches will be chosen instead of others.

\section{Acknowledgements}

The authors wish to thank Mrs. Rina Kampeas and Louise Corbeil for editorial work on the manuscript.

\section{Funding}

This work was supported by the research grant from the Canadian Institutes of Health Research (CIHR grant number 142187 awarded to JP). The funding agency did not have any involvement in data collection, analysis and interpretation, as well as in the writing of this manuscript.

\section{Authors' Contributions}

All authors contributed to the study design. GAL, JP, PD, CAB and SKB reviewed the literature. GAL, JP, JPB and MP extracted the citations. The HTA professionals (SKB, CAB, PD) helped to categorize the results. GAL, JP and HG drafted the text of this article. PD, SKB, CAB, CED, JPB, MP and LB critically revised the text of this article. All authors read and approved the final version this manuscript.

\section{Conflicts of Interest}

The authors declare no conflicts of interest regarding the publication of this paper.

\section{References}

Assasi, N., Schwartz, L., Tarride, J. E., Campbell, K., \& Goeree, R. (2014). Methodological Guidance Documents for Evaluation of Ethical Considerations in Health Technology Assessment: A Systematic Review. Expert Review of Pharmacoeconomics \& Outcomes Research, 14, 203-220. https://doi.org/10.1586/14737167.2014.894464

Assasi, N., Schwartz, L., Tarride, J. E., O’Reilly, D., \& Goeree, R. (2015). Barriers and Facilitators Influencing Ethical Evaluation in Health Technology Assessment. International Journal of Technology Assessment in Health Care, 31, 113-123. 
https://doi.org/10.1017/S026646231500032X

Assasi, N., Tarride, J. E., O’Reilly, D., \& Schwartz, L. (2016). Steps toward Improving Ethical Evaluation in Health Technology Assessment: A Proposed Framework. BMC Medical Ethics, 17, 34. https://doi.org/10.1186/s12910-016-0118-0

Béland, J. P., Patenaude, J., Legault, G. A., Boissy, P., \& Parent, M. (2011). The Social and Ethical Acceptability of NBICs for Purposes of Human Enhancement: Why Does the Debate Remain Mired in Impasse? Nanoethics, 5, 295-307. https://doi.org/10.1007/s11569-011-0133-Z

Bellemare, C. A. et al. (2018). Ethics in Health Technology Assessment: A Systematic Review. International Journal of Technology Assessment in Health Care, 34, 447-457. https://doi.org/10.1017/S0266462318000508

Bombard, Y., Abelson, J., Simeonov, D. \& Gauvin, F. P. (2011). Eliciting Ethical and Social Values in Health Technology Assessment: A Participatory Approach. Social Science \& Medicine, 73, 135-144. https://doi.org/10.1016/j.socscimed.2011.04.017

Braunack-Mayer, A. J. (2006). Ethics and Health Technology Assessment: Handmaiden and/or Critic? International Journal of Technology Assessment in Health Care, 22, 307-312. https://doi.org/10.1017/S0266462306051191

Campbell Black, H. (2017). The Law Dictionary. http://thelawdictionary.org/ethical-issue/

Daniels, N., \& van der Wilt, G. J. (2016). Health Technology Assessment, Deliberative Process, and Ethically Contested Issues. International Journal of Technology Assessment in Health Care, 32, 10-15. https://doi.org/10.1017/S0266462316000155

European Network for Health Technology Assessment (EUnetHTA) (2016). Joint Action 2, Work Package 8: HTA Core Model. http://www.htacoremodel.info/BrowseModel.aspx

Fletcher, J. F. (1966). Situation Ethics: The New Morality. Philadelphia, PA: Westminster Press.

Hofmann, B. (2005a). On Value-Judgments and Ethics in Health Technology Assessment. Poiesis und Praxis, 3, 277-295. https://doi.org/10.1007/s10202-005-0073-1

Hofmann, B. (2005b). Toward a Procedure for Integrating Moral Issues in Health Technology Assessment. International Journal of Technology Assessment in Health Care, 21, 312-318. https://doi.org/10.1017/S0266462305050415

Hofmann, B. (2013). Health Technology Assessment-Science or Art? GMS Health Technology Assessment, 9, 1-8.

Hofmann, B. (2014). Why Not Integrate Ethics in HTA: Identification and Assessment of the Reasons. GMS Health Technology Assessment, 10, Doc04.

Hofmann, B. et al. (2015). Integrating Ethics in Health Technology Assessment: Many Ways to Rome. International Journal of Technology Assessment in Health Care, 31, 131-137. https://doi.org/10.1017/S0266462315000276

Hofmann, B. M. (2008). Why Ethics Should Be Part of Health Technology Assessment. International Journal of Technology Assessment in Health Care, 24, 423-429.

Hofmann, B., Droste, S., Oortwijn, W., Cleemput, I., \& Sacchini, D. (2014). Harmonization of Ethics in Health Technology Assessment: A Revision of the Socratic Approach. International Journal of Technology Assessment in Health Care, 30, 3-9. https://doi.org/10.1017/S0266462313000688

Jonsen, A. R., \& Toulmin, S. E. (1988). The Abuse of Casuistry: A History of Moral Reasoning. Oakland, CA: University of California Press.

Legault, G. A. (2014). Redéfinir la philosophie à l'ère de la technoscience : La raison pratique. In A. Lacroix (Ed.), Quand la philosophie doit s' appliquer (p. 294). Paris, France: 
Hermann Philosophie.

Legault, G. A. et al. (2018). Revisiting the Fact/Value Dichotomy: A Speech Act Approach to Improve the Integration of Ethics in Health Technology. Open Journal of Philosophy, 8, 578-593. https://doi.org/10.4236/ojpp.2018.85042

Legault, G. A., Patenaude, J., Béland, J. P., \& Parent, M. (2013). Nanotechnologies and Ethical Argumentation: A Philosophical Stalemate? Open Journal of Philosophy, 3, 15-22. https://doi.org/10.4236/ojpp.2013.31004

Lehoux, P., \& Williams-Jones, B. (2007). Mapping the Integration of Social and Ethical Issues in Health Technology Assessment. International Journal of Technology Assessment in Health Care, 23, 9-16. https://doi.org/10.1017/S0266462307051513

Liberati, A., Sheldon, T. A., \& Banta, H. D. (1997). EUR-ASSESS Project Subgroup Report on Methodology: Methodological Guidance for the Conduct of Health Technology Assessment. International Journal of Technology Assessment \& Health Care, 13, 186-219. https://doi.org/10.1017/S0266462300010369

Lysdahl, K. B. et al. (2016). Ethical Analysis in HTA of Complex Health Interventions. BMC Medical Ethics, 17, 16. https://doi.org/10.1186/s12910-016-0099-Z

Park, S. Y., Kwon, I., \& Oh, I. H. (2016). Burden of Disease Study and Priority Setting in Korea: An Ethical Perspective. Journal of Korean Medical Science, 31, S108-S113. https://doi.org/10.3346/jkms.2016.31.S2.S108

http://ovidsp.ovid.com/ovidweb.cgi?T=JS\&CSC=Y\&NEWS=N\&PAGE=fulltext\&D=pr $\underline{\mathrm{em} \& \mathrm{AN}=27775247}$

Patenaude, J. et al. (2015). Framework for the Analysis of Nanotechnologies' Impacts and Ethical Acceptability: Basis of an Interdisciplinary Approach to Assessing Novel Technologies. Science and Engineering Ethics, 21, 293-315.

https://doi.org/10.1007/s11948-014-9543-y

Patenaude, J., Legault, G. A., Béland, J. P., Parent, M., \& Boissy, P. (2011). Moral Arguments in the Debate over Nanotechnologies: Are We Talking Past Each Other? Nanoethics, 5, 285-293. https://doi.org/10.1007/s11569-011-0132-0

Reuzel, R. et al. (2004). Ethics and HTA: Some Lessons and Challenges for the Future. Poiesis \& Praxis, 2, 247-256. https://doi.org/10.1007/s10202-003-0054-1

Reuzel, R. P., van der Wilt, G. J., ten Have, H. A. M. J., \& de Vries Robbé, P. F. (1999). Reducing Normative Bias in Health Technology Assessment: Interactive Evaluation and Casuistry. Medicine, Health Care \& Philosophy, 2, 255-263.

https://doi.org/10.1023/A:1009963018813

Saarni, S. I. et al. (2008). Ethical Analysis to Improve Decision-Making on Health Technologies. Bulletin of the World Health Organization, 86, 617-623. https://doi.org/10.2471/BLT.08.051078

Saarni, S. I., Braunack-Mayer, A., Hofmann, B., \& van der Wilt, G. J. (2011). Different Methods for Ethical Analysis in Health Technology Assessment: An Empirical Study. International Journal of Technology Assessment in Health Care, 27, 305-312. https://doi.org/10.1017/S0266462311000444

Sacchini, D., Virdis, A., Refolo, P., Pennacchini, M., \& Carrasco de Paula, I. (2009). Health Technology Assessment (HTA): Ethical Aspects. Medicine, Health Care \& Philosophy, 12, 453-457. https://doi.org/10.1007/s11019-009-9206-y

WHO (2019). HTA Definition.

https://www.who.int/health-technology-assessment/about/Defining/en/

WHO-HTA (2017). WHO: Medical Devices.

http://www.who.int/medical_devices/assessment/en/ 


\section{Abbreviations}

HTA: Health Technology Assessment

CA: Coherence Analysis

WRE: Wide Reflective Equilibrium

CTA: Constructive Technology Assessment

SST: Social Shaping of Technology 